\title{
Klebsiella ozaenae
}

National Cancer Institute

\section{Source}

National Cancer Institute. Klebsiella ozaenae. NCI Thesaurus. Code C86456.

A species of facultatively anaerobic, Gram negative, rod shaped bacteria assigned to the phylum Proteobacteria. This species is nonmotile, oxidase and indole negative, encapsulated and lactose fermenting. K. pneumoniae is part of the normal flora of the mouth, intestines, and skin but may become pathogenic; it is the causative agent of Klebsiella pneumonia in immunocompromised, diabetic, and alcoholic patients. 